\title{
The effect of restorative dentistry practices on the vital signs of healthy individuals
}

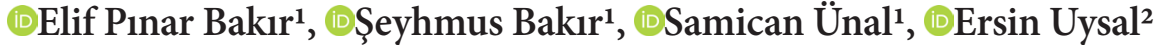 \\ ${ }^{1}$ Dicle University, Faculty of Dentistry, Department of Restorative Dentistry, Diyarbakır, Turkey \\ ${ }^{2}$ Dicle University, Vocational School of Technical Sciences, Department of Computer Technologies, Diyarbakur, Turkey
}

Cite this article as: Bakır EP, Bakır Ş, Ünal S, Uysal E. The effect of restorative dentistry practices on the vital signs of healthy individuals. J Health Sci Med 2021; 4(4): 434-440.

\begin{abstract}
Aim: Clinical applications of dentistry, the tools and drugs used increase the effects of anxiety and stress factors that we encounter before the treatment, but also cause changes in the life symptoms of the patients. In this study, it is aimed to evaluate the effects of Restorative Dentistry applications on vital signs parameters such as blood pressure, heart rate, body temperature and oxygen saturation of healthy individuals before and after the interventional procedure.

Material and Method: In the study, blood pressure, pulse rate, body temperature and oxygen saturation values of 100 patients without any systemic disease were measured before clinical applications. Following the treatment intervention, the same parameters were measured again and evaluated by comparing the previous and next values.

Result: In the patients who were not applied local anesthesia, the post-treatment measurement values of the body temperature parameter were significantly higher than the initial measurement values $(\mathrm{p}<0.05)$. There was no statistically significant difference between the first and last measurement values of other parameters $(\mathrm{p}>0.05)$. In patients who were applied local anesthesia, the last measurement values of body temperature and systolic blood pressure were significantly lower than the initial measurement values $(\mathrm{p}<0.05)$. There was no statistically significant difference between the first and last measurement values of diastolic blood pressure and other parameters $(\mathrm{p}>0.05)$.

Conclusion: We think that measures such as a relationship based on mutual trust, approaching expectations with understanding, informing about interventional procedures and operating consent processes will prevent patients from anxiety during the session and keep vital parameter values at a normal level.
\end{abstract}

Keywords: Restorative dentistry, blood pressure, body temperature, oxygen saturation, pulse

\section{INTRODUCTION}

Vital findings are the parameters that determine the basic functions and physiological state of the body, in short, whether a person is healthy or not. Any deviation from the basic functions of the body is considered a sign of illness. The most important basic vital signs are body temperature, blood pressure, pulse rate and respiratory rate. Today, while oxygen saturation and pain parameters are evaluated as vital signs, the idea that blood glucose level is the vital parameter is not adopted $(1,2)$.

It is possible for the body to carry out its normal functions if the body temperature remains constant within a certain limit. The hypothalamus region of the brain plays an important role in regulating body temperature. The most important factors affecting body temperature are age, gender, physical activity, daily heat cycle, emotional state, environment, hormonal factors and some drugs used $(3,4)$.
The average body temperature of a healthy young adult is higher than that of the elderly, and ranges from about $36-38^{\circ} \mathrm{C}$. Normal body temperature in women varies compared to men, depending on the hormonal effect. Body temperature, which is low in the morning, rises during the day. In addition, with the stimulation of the sympathetic nervous system due to the increase in stress, the amount of epinephrine and norepinephrine secretion increases, metabolism accelerates and body temperature rises (4). Body temperature can be measured by conventional methods (oral, underarm, ear, rectal) or non-contact infrared thermometers. It is easy to use and it is possible to read the body temperature from the indicator in these battery operated thermometers (3).

Blood pressure refers to the pressure that blood exerts on the artery wall. Blood pressure is expressed in terms of 
mercury pressure per $\mathrm{mm}^{2}(\mathrm{~mm} / \mathrm{Hg})$. During heartbeat, two different pressure values called systolic and diastolic are formed in the vessel. The normal value of systolic blood pressure in an adult individual, which is defined as the highest pressure exerted by the blood on the vascular wall during the contraction of the heart, is 120 mmHg. It is accepted that the normal value of diastolic blood pressure in an adult individual is $80 \mathrm{mmHg}$, which is defined as the lowest blood pressure measured at the vascular wall during heart relaxation (3).

Blood pressure measurement can be performed on both arms of an individual sitting and at rest. Repeated measurements should generally be based on the measurement in the arm where the higher value is obtained. Constant blood pressure out of normal values is considered a sign of illness. There may be only systolic or diastolic pressure increase, or both can be seen (3).

The main factors affecting blood pressure are age, gender, race, diet, smoking and alcohol use, physical exercise and some diseases. Blood pressure increases due to the increase in heart rate due to the stimulation of the sympathetic nervous system by some psychological factors such as pain or anxiety. In addition, some narcotic analgesics can cause low blood pressure (4-6). Blood pressure is measured with different blood pressure devices (mercury, mechanical and electronic) called sphygmomanometers. The most widely used technique is the auscultation technique, in which a stethoscope is also used in addition to the sphygmomanometer (2).

In each contraction of the heart, some blood is thrown into the arteries and vessel dilation occurs. This enlargement can be easily felt where the veins are close to the skin surface. This condition, which is repeated with every contraction of the heart, is defined as a pulse. Pulse rate, defined as the heart's rate of beats per minute, is an indicator of heart rate and rhythm (2). The resting heart rate in a healthy adult is between 60 and 100 per minute $(3,4)$.

The main factors affecting the pulse rate are age, weight, physical exercise, high fever, bleeding, pain, systemic diseases, emotional stress and some medications used. While the pulse rate is higher at a young age, it decreases over time. In case of acute pain and increased anxiety, the pulse increases with the stimulation of the sympathetic system. In addition, chronic and long-term pains slow the pulse by stimulating the parasympathetic system. With the increase in blood volume, the pulse feels fuller. The radial artery is the area where the peripheral pulse is taken most easily in adults. The radial artery is easier to localize $(3,4)$.

The easiest symptom to evaluate among vital signs is respiration. Respiratory rate is the number of breaths given by an individual per minute, and the resting respiratory rate in a healthy adult varies between 1620 per minute. For approximately every 4 heartbeats, 1 breathing occurs. As the amount of $\mathrm{CO}_{2}$ in the blood increases, the number and depth of breathing increases (1). The main factors affecting respiration are age, body temperature, physical exercise, some diseases and some medications used. In children and individuals over the age of 65 , the respiratory rate tends to be higher. Pain and some psychological problems stimulate the sympathetic nervous system, thus increasing the speed and depth of breathing. Narcotic analgesics (morphine, diazem, etc.) negatively affect the rate and depth of respiration $(3,4)$.

Oxygen saturation refers to the oxygen level in the blood circulation of the individual. Under normal conditions, the blood oxygen saturation level of a healthy person should be between 90 and 100. Devices that can measure the oxygen level in the blood in the easiest and fastest way are called pulse oximeters. With these devices, the percentage of hemoglobin saturated with oxygen is measured and recorded as peripheral oxygen saturation $\left(\mathrm{SpO}_{2}\right)(1,2,7)$.

The emotional stress that the patient is exposed to before or during dental treatment is called dental anxiety. These types of stress and anxiety cause changes in vital signs, especially cardiovascular and respiratory systems $(6,7)$. The patient's age, gender, personality, expectations, previous treatment experiences and fear of local anesthesia are factors affecting the anxiety level. It is inevitable that such anxieties affect many parameters such as body temperature, blood pressure, pulse and respiratory rate, as well as mental state and behavior $(2,5,6)$.

The aim of this study is to examine the effect of restorative treatment procedures on vital parameters (body temperature, blood pressure, pulse rate and oxygen saturation) measured before and after treatment and to investigate whether these changes remain within physiological limits.

\section{MATERIAL AND METHOD}

\section{Participants}

In our study, a total of 100 people (50 females, 50 males), between the ages of 16-50, who applied to Dicle University University Faculty of Dentistry, Department of Restorative Dentistry and did not have any systemic disease were included in the study. Before and after the interventional procedure, blood pressure, pulse rate, body temperature and oxygen saturation values were measured twice in total, and the informed consent form was read and signed by the patients to be compared. 


\section{Ethics Statement}

Participants were informed about the purpose of the study and their consent was obtained by paying attention to the principle of volunteering. It was also ensured that the information about the participants would be kept confidential. Approval for the study was given by the Ethics Committee of Dicle University University Faculty of Dentistry (Date: 29.05.2019, Decision No: 2019/6). All procedures were carried out in accordance with the ethical rules and the principles of the Declaration of Helsinki.

\section{Evaluation of Vital Signs}

Clinical and radiological examinations of the patients whose anamnesis were taken were made and their treatments were started. Before the procedure, the vital signs of the patients who underwent routine restorative dental procedures such as cavity opening, placement of the base material, application of the adhesive system, composite resin restoration were measured and recorded. After routine treatment procedures, the effects of the procedures performed by measuring the vital signs for a second time on the vital signs parameters and whether they are within the physiological limits were investigated.

A manual sphygmomanometer with a stethoscope was used to measure systolic and diastolic blood pressure values and recorded in mmHg. Pulse rate values as well as oxygen saturation were determined with the pulse oximeter device attached to the fingertip. Body temperature was measured and recorded in degrees Celsius with a non-contact digital thermometer.

\section{RESULTS}

The data recorded before and after the treatment were analyzed with IBM SPSS Statistics package program. The Shapiro-Wilk test was used to investigate the status of the variables coming from the normal distribution, due to the unit numbers. While examining the intragroup differences, Paired Samples T-Test was used as the variables came from normal distribution. While interpreting the results, the level of significance was determined as 0.05 , it was stated that there was a significant difference when $\mathrm{p}<0.05$, and that the difference was not significant when $\mathrm{p}>0.05$.

In patients who did not undergo local anesthesia, a statistically significant difference was observed between the first and last measurement values in terms of only the body temperature parameter $(p<0.05)$. The last measurement values of body temperature were significantly higher than the first measurements (Figure 1). There was no significant difference between the first and last measurement values of other parameters $(\mathrm{p}>0.05)$.
A statistically significant difference was found between the first and last measurement values in terms of fever and systolic blood pressure parameters in patients undergoing local anesthesia $(\mathrm{p}<0.05)$. While the last measurement values of body temperature were significantly higher than the first measurements, the last measurement values of systolic blood pressure were found to be significantly lower than the first measurements (Figure 2). There was no significant difference between the first and last measurement values of other parameters $(p>0.05)$. Regardless of the anesthesia application, a positive and moderately significant correlation was found between the first and last measurement values of all parameters $(\mathrm{p}<0.05)$.

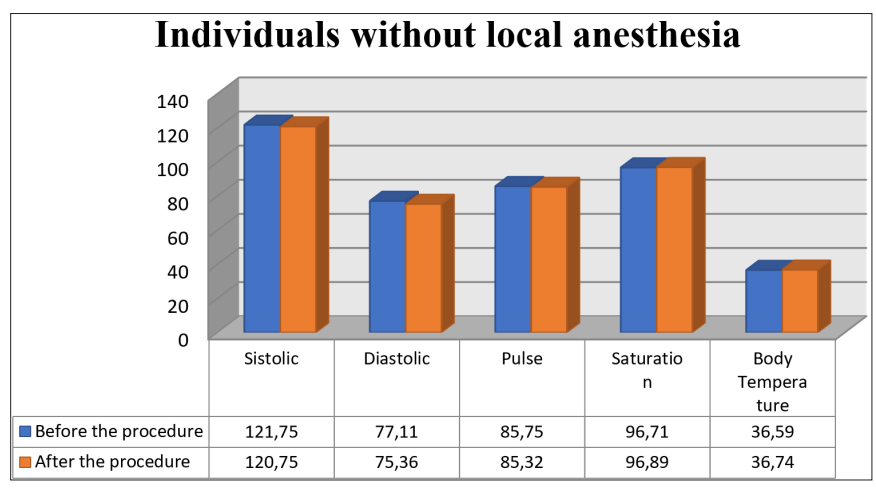

Figure 1. The distribution of vital signs measurement values before and after the procedure in patients who were not applied local anesthesia.

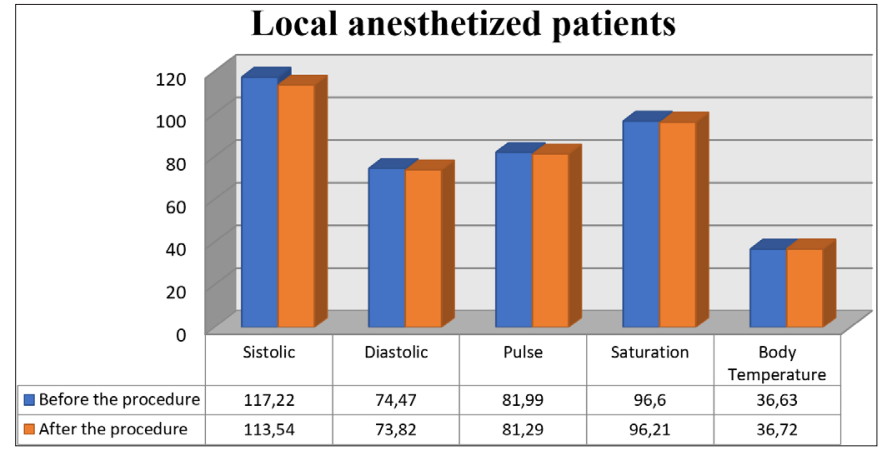

Figure 2. Distribution of vital signs measurement values before and after the procedure in locally anesthetized patients.

In all male and female patients, a statistically significant difference was observed between the first and last measurement values in terms of only the body temperature parameter $(\mathrm{p}<0.05)$. The last measurement values of body temperature were significantly higher than the first measurements (Figure 3,4). There was no significant difference between the first and last measurement values of other parameters ( $p>0.05)$. When the first and last values of the saturation parameter were excluded in female patients, a positive and moderately significant correlation was found between the first and last measurement values of all other parameters, regardless of gender $(\mathrm{p}<0.05)$. 


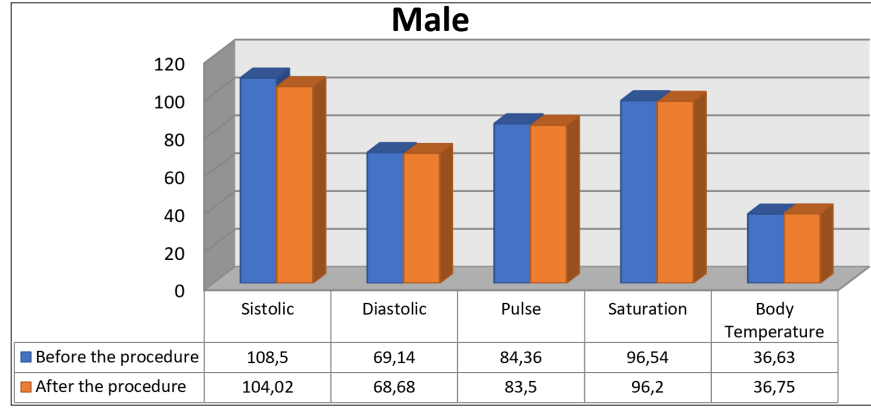

Figure 3. Distribution of vital signs measurement values before and after the procedure in male patients

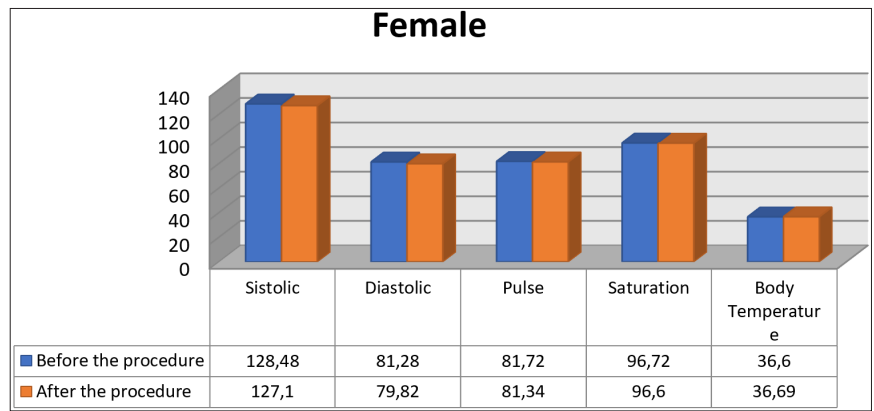

Figure 4. Distribution of vital signs measurement values before and after the procedure in female patients

\section{DISCUSSION}

Clinical practices in dentistry cause changes in the life symptoms of patients by increasing the effects of anxiety and stress factors. Anxiety has been defined as an emotional response accompanied by physical symptoms. It is a pathological uneasiness condition that is generally seen at different times in every person and develops due to fear. After a certain stage, it causes mental problems and negatively affects the vital activities and relationships of the individual. For example, blood pressure and pulse increase in the person, and physiological symptoms similar to sweating occur $(10,11)$.

Dental anxiety is expressed as the feeling that bad things will happen during the dental treatment of the patient and the anxiety of feeling pain. Today, despite the widespread use of local anesthetics and analgesics, the absence of a decrease in the frequency and severity of dental anxiety refutes the idea that the main etiological factor is pain. In addition to the negative experiences of the person in the past, rotary devices, light devices, amalgam and compomer guns, hand tools such as probe and presses, acid injectors, injection process and waiting time also play a role in the increase of such concerns (12).

Patients generally feel more fear during waiting than when they are treated. At the root of this fear lies the anxiety of losing the teeth or physical integrity, especially the pain. The most important clinical findings are irregularity in breathing, tightening of the teeth and jaw, muscle tension, sudden silence of a talkative person or excessive conversation of a calm person, the desire to spit frequently and mouthwash, holding the physician's arm, discomfort and restlessness, respectively (12).

Age, gender, education level or socio-economic status are the main factors affecting dental anxiety level. In a study by Gedik et al. (13), they claimed that patient age, gender, education, local anesthetic volume, length of treatment and difficulty of procedure changed body parameters. Especially in young patients, it has been claimed that the level of dental anxiety is higher, however, Ay et al. (14) and Öcek et al. (15) stated that there is no relationship between age and anxiety level. In our study, it was not possible to comment on whether there was a relationship between age and anxiety level, since the distribution of 100 patients between the ages of 16-50 was not homogeneous across age groups.

Studies have shown that the higher anxiety level of women compared to men is not because they fear more, but because they express their feelings more easily (16-18). In their study, Muğlalı and Kömerik (19) attributed the lower dental anxiety level of men to the belief that men in our society should be more durable and brave, and they did not reveal their fears. Özdemir et al. (20) explained that the anxiety level in men is higher than in women. In our study, unlike these studies, no significant difference was found between the anxiety levels of men and women. The last measurement values of body temperature in all male and female patients were significantly higher than the first measurements $(p<0.05)$. There was no significant difference between the first and last measurement values of other parameters $(\mathrm{p}>0.05)$.

It has been reported that patients with high socioeconomic and educational levels have lower dental anxiety levels. It has been claimed that the anxiety levels of the patients decrease with the increase in the level of education and the awareness of the patients (21). This result is explained by the fact that patients with high education level cope more easily with stress. In addition, there are studies that argue that there is no relationship between education level and dental anxiety (22). In our study, the effect of patients' socio-economic status and education level on dental anxiety was excluded.

Informing patients in advance about the procedures to be performed with informed consent will provide some reduction in anxiety (12). However, sharing more than necessary medical details and possible complication information in the consent form may increase the anxiety level of the patients. In a study in which Casap et al. (23) investigated the effect of the informed consent form on the anxiety level of patients, it was stated that the heart rate increased, but blood pressure and saturation did not change statistically. In our study, an enlightened consent form was read before the treatment, and the anxiety of the 
Table 1. Analysis of patients' first and last vital signs according to local anesthesia application status

\begin{tabular}{|c|c|c|c|c|c|c|c|c|}
\hline Anesthesia & $\begin{array}{l}\text { Parameters } \\
\text { Before the procedure (b.p) } \\
\text { After the procedure (a.p) }\end{array}$ & Mean & $\mathbf{N}$ & $\begin{array}{c}\text { Std. } \\
\text { Deviation }\end{array}$ & $\begin{array}{l}\text { Std. Error } \\
\text { mean }\end{array}$ & $\mathbf{P}$ & Correlation & $\mathbf{P}$ \\
\hline \multirow{10}{*}{$\begin{array}{l}\text { Patients without } \\
\text { local anesthesia }\end{array}$} & Sistolic (b.p) & 121.75 & 28 & 13.72 & 2.59 & \multirow{2}{*}{0.698} & \multirow{2}{*}{0.67} & \multirow{2}{*}{0.001} \\
\hline & Sistolic (a.p) & 120.75 & 28 & 18.04 & 3.41 & & & \\
\hline & Diastolic (b.p) & 77.11 & 28 & 11.40 & 2.15 & \multirow{2}{*}{0.355} & \multirow{2}{*}{0.624} & \multirow{2}{*}{0.001} \\
\hline & Diastolic (a.p) & 75.36 & 28 & 11.27 & 2.13 & & & \\
\hline & Pulse (b.p) & 85.75 & 28 & 15.44 & 2.91 & \multirow{2}{*}{0.837} & \multirow{2}{*}{0.707} & \multirow{2}{*}{0.001} \\
\hline & Pulse (a.p) & 85.32 & 28 & 10.99 & 2.07 & & & \\
\hline & Saturation (b.p) & 96.71 & 28 & 2.43 & 0.46 & \multirow{2}{*}{0.624} & \multirow{2}{*}{0.637} & \multirow{2}{*}{0.001} \\
\hline & Saturation (a.p) & 96.89 & 28 & 1.89 & 0.35 & & & \\
\hline & Body temperature (b.p) & 36.59 & 28 & 0.32 & 0.06 & \multirow{2}{*}{0.037} & \multirow{2}{*}{0.403} & \multirow{2}{*}{0.033} \\
\hline & Body temperature (a.p) & 36.73 & 28 & 0.30 & 0.05 & & & \\
\hline \multirow{10}{*}{$\begin{array}{l}\text { Patients } \\
\text { undergoing } \\
\text { local anesthesia }\end{array}$} & Sistolic (b.p) & 117.22 & 72 & 13.98 & 1.64 & \multirow{2}{*}{0.039} & \multirow{2}{*}{0.649} & \multirow{2}{*}{0.001} \\
\hline & Sistolic (a.p) & 113.54 & 72 & 19.43 & 2.29 & & & \\
\hline & Diastolic (b.p) & 74.47 & 72 & 12.40 & 1.46 & \multirow{2}{*}{0.464} & \multirow{2}{*}{0.82} & \multirow{2}{*}{0.001} \\
\hline & Diastolic (a.p) & 73.82 & 72 & 12.64 & 1.49 & & & \\
\hline & Pulse (b.p) & 81.99 & 72 & 10.94 & 1.29 & \multirow{2}{*}{0.411} & \multirow{2}{*}{0.771} & \multirow{2}{*}{0.001} \\
\hline & Pulse (a.p) & 81.29 & 72 & 9.92 & 1.16 & & & \\
\hline & Saturation (b.p) & 96.60 & 72 & 2.10 & 0.24 & \multirow{2}{*}{0.186} & \multirow{2}{*}{0.316} & \multirow{2}{*}{0.007} \\
\hline & Saturation (a.p) & 96.21 & 72 & 2.11 & 0.24 & & & \\
\hline & Body temperature (b.p) & 36.62 & 72 & 0.30 & 0.03 & \multirow{2}{*}{0.011} & \multirow{2}{*}{0.477} & \multirow{2}{*}{0.001} \\
\hline & Body temperature (a.p) & 36.71 & 72 & 0.27 & 0.03 & & & \\
\hline
\end{tabular}

\section{Table 2. Analysis of patients' first and last vital signs by gender}

\begin{tabular}{|c|c|c|c|c|c|c|c|c|}
\hline Gender & $\begin{array}{l}\text { Parameters } \\
\text { Before the procedure (b.p) } \\
\text { After the procedure (a.p) }\end{array}$ & Mean & $\mathbf{N}$ & $\begin{array}{c}\text { Std. } \\
\text { Deviation }\end{array}$ & Std. Error mean & $\mathbf{P}$ & Correlation & $\mathbf{P}$ \\
\hline \multirow{10}{*}{ Male } & Sistolic (b.p) & 108.5 & 50 & 10.35 & 1.46 & \multirow{2}{*}{0.064} & \multirow{2}{*}{0.368} & \multirow{2}{*}{0.009} \\
\hline & Sistolic (a.p) & 104.02 & 50 & 17.44 & 2.46 & & & \\
\hline & Diastolic (b.p) & 69.14 & 50 & 10.45 & 1.47 & \multirow{2}{*}{0.712} & \multirow{2}{*}{0.678} & \multirow{2}{*}{0.001} \\
\hline & Diastolic (a.p) & 68.68 & 50 & 11.26 & 1.59 & & & \\
\hline & Pulse (b.p) & 84.36 & 50 & 12.62 & 1.78 & \multirow{2}{*}{0.465} & \multirow{2}{*}{0.762} & \multirow{2}{*}{0.001} \\
\hline & Pulse (a.p) & 83.5 & 50 & 10.76 & 1.52 & & & \\
\hline & Saturation (b.p) & 96.54 & 50 & 2.565 & 0.36 & \multirow{2}{*}{0.34} & \multirow{2}{*}{0.49} & \multirow{2}{*}{0.001} \\
\hline & Saturation (a.p) & 96.2 & 50 & 2.365 & 0.33 & & & \\
\hline & Body temperature (b.p) & 36.634 & 50 & 0.3402 & 0.048 & \multirow{2}{*}{0.016} & \multirow{2}{*}{0.467} & \multirow{2}{*}{0.001} \\
\hline & Body temperature (a.p) & 36.754 & 50 & 0.3208 & 0.04 & & & \\
\hline \multirow{10}{*}{ Female } & Sistolic (b.p) & 128.48 & 50 & 9.20 & 1.30 & \multirow{2}{*}{0.413} & \multirow{2}{*}{0.485} & \multirow{2}{*}{0.001} \\
\hline & Sistolic (a.p) & 127.1 & 50 & 13.11 & 1.85 & & & \\
\hline & Diastolic (b.p) & 81.28 & 50 & 10.62 & 1.50 & \multirow{2}{*}{0.185} & \multirow{2}{*}{0.739} & \multirow{2}{*}{0.001} \\
\hline & Diastolic (a.p) & 79.82 & 50 & 10.62 & 1.50 & & & \\
\hline & Pulse (b.p) & 81.72 & 50 & 12.16 & 1.72 & \multirow{2}{*}{0.751} & \multirow{2}{*}{0.726} & \multirow{2}{*}{0.001} \\
\hline & Pulse (a.p) & 81.34 & 50 & 9.88 & 1.39 & & & \\
\hline & Saturation (b.p) & 96.72 & 50 & 1.76 & 0.24 & \multirow{2}{*}{0.698} & \multirow{2}{*}{0.224} & \multirow{2}{*}{0.118} \\
\hline & Saturation (a.p) & 96.6 & 50 & 1.72 & 0.24 & & & \\
\hline & Body temperature (b.p) & 36.598 & 50 & 0.2818 & 0.0398 & \multirow{2}{*}{0.024} & \multirow{2}{*}{0.421} & \multirow{2}{*}{0.002} \\
\hline & Body temperature (a.p) & 36.69 & 50 & 0.2288 & 0.0324 & & & \\
\hline
\end{tabular}

patients was tried to be reduced by making explanations about the procedure to be performed.

The level at which various dental practices affect anxiety levels is also different. Wong and Lyte (24) in a study where they examined the effects of 8 different dental procedures on anxiety levels, concluded that there was a higher anxiety towards root canal treatment and surgical procedures. While a moderate level of anxiety developed against restorative treatment and prosthetic procedures, a low anxiety response occurred to tartar cleaning and examination procedures.

Dental anxiety decreases the quality of life of the person and can cause changes in body temperature, blood pressure, pulse and respiratory rate as well as psychosomatic symptoms (25). In a study by Salma et al. (6), it was determined that even a simple treatment 
intervention has an impact on vital values. They reported that tooth extraction, tartar cleaning and restorative treatment procedures cause an increase in body temperature and oxygen saturation values. Gedik et al. (9) reported that blood pressure, heart rate and body temperature decreased significantly after gingivectomy, and that blood pressure and pulse did not change after frenectomy and curettage procedures, but body temperature increased significantly. In our study, the last measurement value of body temperature was found to be significantly higher than the first measurement in patients who were not applied local anesthesia and who were applied local anesthesia with vasoconstrictor $(\mathrm{p}<0.05)$. Excluding systolic blood pressure, no significant difference was found between the first and last measurement values of the other parameters $(p>0.05)$.

It is claimed that local anesthesia and preparation procedures cause higher anxiety in terms of image and sound. Even if the anesthesia procedure will make the treatment application painless, it increases the anxiety level of the patient before the treatment. Nakamura et al. (26) stated that local anesthesia applied to the patient before dental surgery caused a significant increase in heart rate and systolic blood pressure. Elad et al. (27) reported that while restorative treatments performed under dental anesthesia in patients with a history of ischemic heart disease, insignificant increases in systolic blood pressure were recorded, there was no change in the number of heartbeats. In our study, contrary to these findings, the last measurement values of systolic blood pressure were found to be significantly lower than the first measurements in patients who underwent local anesthesia with vasoconstrictor $(\mathrm{p}<0.05)$. Excluding body temperature, there was no significant difference between the first and last measurement values of the other parameters $(\mathrm{p}>0.05)$.

Tomeva et al. (28), in a study in which they evaluated vital signs and hemodynamic changes after local anesthesia, did not find an increase in systolic and diastolic blood pressure, they explained that the pulse rate changed slightly, but this change was not statistically significant.

Salma et al. emphasized that the oxygen saturation value during local anesthesia injection exceeded normal physiological limits in some patients compared to the treatment procedure (6). Amoian et al. (29) stated that there is no statistically significant difference in the oxygen saturation level measured by pulse oximetry at different stages of periodontal surgery. Alemany-Martinez et al. (30) also observed the pulse, blood pressure and oxygen saturation values of healthy patients during the extraction of mandibular 3rd molar teeth under local anesthesia. It was determined that the increase in pulse rate observed during the surgical incision in patients with high anxiety returned to normal after a while. It has been reported that systolic and diastolic blood pressure increased slightly and there was no significant change in oxygen saturation value during osteotomy and dissection of the tooth.

The vasoconstrictor nature of local anesthesia can cause cardiovascular complications in addition to catecholamine secretion in patients with anxiety (30). In a different study by Mohammad Ketabi et al. (13), it was stated that the application of local anesthesia with vasoconstrictor increased blood pressure and pulse rate, but this increase was within medically and clinically normal limits. Laragnoit et al. (25) reported that there was no increase in heart rate and blood pressure during dental treatments where they applied vasoconstrictor local anesthesia on people with heart disease. Güngörmiş et al. (31) could not detect a significant effect on blood pressure and pulse values in patients who used vasoconstrictor local anesthesia. Faraco et al. (32) examined the effects of anesthetics containing epinephrine and lidocaine on the cardiovascular system during dental implant surgery and emphasized that there was no significant change in blood pressure and pulse values . In our study, it was concluded that the vital signs parameters were not significantly affected by the restorative treatment procedures in the evaluations made considering the gender difference and whether local anesthesia was performed or not.

Most of the dentists worry about dental anxiety patients and do not know what to do and do not try to solve the problem. We think this is due to lack of information. In dental treatment of such patients, pharmacological methods, behavioral approaches, additional time, patience and energy are needed. Patients with high levels of anxiety can usually cope with this, with some encouragement. In addition, it is witnessed that the level of dental anxiety spontaneously decreases over time without any physician or patient effort.

\section{CONCLUSIONS}

To establish a relationship based on mutual trust and empathy, to approach their concerns and special requests with understanding, to continue communication during the examination and treatment process, to make them think that no action will be taken that they do not allow, and to inform patients about interventional procedures in advance (tell-show-apply strategy) during the session. It will help him relax by preventing his anxiety.

\section{ETHICAL DECLARATIONS}

Ethics Committee Approval: Approval for the study was given by the Ethics Committee of Dicle University University Faculty of Dentistry (Date: 29.05.2019, Decision No: 2019/6). 
Informed Consent: All patients signed the free and informed consent form.

Referee Evaluation Process: Externally peer-reviewed.

Conflict of Interest Statement: The authors have no conflicts of interest to declare.

Financial Disclosure: The authors declared that this study has received no financial support.

Author Contributions: All of the authors declare that they have all participated in the design, execution, and analysis of the paper, and that they have approved the final version.

Acknowledgements: We would like to thank all healthcare professionals that agreed to share their perspectives.

\section{REFERENCES}

1. Ball JW, Dains JE, Flynn JA, Solomon BS, Stewart RW. Vital signs and pain assessment. Seidel's Guide to Physical Examination. Elsevier/Mosby; 2015: 50-63.

2. Goldman L, Schafer AI. Goldman-Cecil Medicine E-Book. 25th ed. St. Louis, MO: Elsevie Health Sciences; 2015.

3. TC. Milli Eğitim Bakanlığı Yașam (Vital) Bulguları. Hemșirelik. Ankara 2012; 1-68.

4. TC. Milli Eğitim Bakanlığı Vital Bulgular. Anestezi ve Reanimasyon. Ankara 2011; 1-98.

5. Parati G, Stergiou GS, Asmar R, et al. European Society of Hypertension Practice Guidelines for home blood pressure monitoring. J Hum Hypertens 2010; 24: 779-85.

6. Salma RG, Abu-Naim H, Ahmad O, Akelah D, Salem Y, Midoun E. Vital signs changes during different dental procedures: A prospective longitudinal cross-over clinical trial. Oral Medicine 2019; 127: 30-9.

7. Rodríguez-Molinero A, Narvaiza L, Ruiz J, Gálvez-Barrón C. Normal respiratory rate and peripheral blood oxygen saturation in the elderly population. J Am Geriatr Soc 2013; 61: 2238-40

8. Guyton AC, Hall JE. Guyton and Hall textbook of medical physiology. 11th Ed Philadelphia PA: Saunders Elsevier 2006.

9. Gedik RG, Marakoglu I, Demirer S. Blood pressure, heart rate and temperature variability during periodontal surgery. West Indian Med J 2005; 54: 329-33.

10. Tillfors M, El-Khouri B, Stein MB, Trost K. Relationships between social anxiety, depressive symptoms and antisocial behaviors: evidence from a prospective study of adolescent boys. J Anxiety Disord 2009; 23: 718-24

11. Ruscio AM, et al. Broadening the definition of generalized anxiety disorder: effects on prevalence and associations with other disorders in the National Comorbidity Survey Replication. J Anxiety Disord 2007; 21: 662-76.

12. Ayaz A, Bilgin N, Mollaoğlu N. The use of stait-trait anxiety inventory in dental anxiety management. ADO J Clin Sci 2017; 8: $1553-60$.

13. Ketabi M, Shamami S, Alaie M, Shamami MS. Influence of local anesthetics with or without epinephrine 1/80000 on blood pressure and heart rate: A randomized double-blind experimental clinical trial. Dent Res J (Isfahan) 2012; 9: 437-40.

14. Ay S, Özdemir D, Öztürk M, Polat S. An assesment of dental anxiety in oral surgery patients. Gülhane Tip Derg 2002; 4484: 395-8.

15.Öcek ZA, Karababa AO, Türk M, Çiçeklioğlu M. Assessment of aetiology of dental anxiety of patients applying to Ege University, School of Dentistry. Ege Üni Diş Hek Fak Derg 2001: 22; 121-9.
16. Armfield JM, Spencer AJ, Stewart JF. Dental fear in Australia: who's afraid of the dentist? Aust Dent J 2006; 51: 78-85.

17. Matthias AT, Samarasekera DN. Preoperative anxiety in surgical patients-experience of a single unit. Acta Anaesthesiol Taiwan 2012; 50: 3-6.

18.18.Garip H, Abali O, Goker K, Gokturk U, Garip Y. Anxiety and extraction of third molars in Turkish patients. Br J Oral Maxillofac Surg 2004; 42: 551-4.

19. Muğlalı M, Kömerik N. Oral surgery and anxiety. Cumhuriyet Üni Diş Hek Fak Derg 2005; 8: 83-8.

20. Özdemir AK, Özdemir HD, Coskun A, Taşveren S. Investigation of a patient's anxiety in other clinics with denture clinic in faculty of dentistry. Cumhuriyet Üniversitesi Dișhekimliği Fakültesi Derg 2001; 4: 71-4.

21.Menziletoğlu D, Akbulut MB, Büyükerkmen EB, Işık BK. The evaluation of dental fear and anxiety levels of preclinical and clinical dental students. Selcuk Dent J, 2018; 5: 22-30.

22. Sezer U, Üstün K, Şenyurt SZ, Çiftçi ME, Erciyas K. The evaluation ofanxiety in periodontal patients. Cumhuriyet Dent J 2012; 15: 297-306.

23. Casap N, Alterman M, Sharon G, Samuni Y. The effect of informed consent on stress levels associated with extraction of impacted mandibular third molars. J Oral Maxillofac Surg 2008; 66: 878-81.

24. Wong M, Lytle WR. A comparison of anxiety levels associated with root canal therapy and oral surgery treatment. J Endod 1991; 17: 461-5.

25.Laragnoit AB, Neves RS, Neves IL, Vieira JE. Locoregional anesthesia for dental treatment in cardiac patients: a comparative study of $2 \%$ plain lidocaine and $2 \%$ lidocaine with epinephrine (1:100,000). Clinics (Sao Paulo) 2009; 64: 177-82.

26. Nakamura Y, Matsumura K, Miura K, Kurokawa H, Abe I, Takata Y. Cardiovascular and sympathetic responses to dental surgery with local anesthesia. Hypertens Res 2001; 24: 209-14.

27.Elad S, Admon D, Kedmi M, et al. The cardiovascular effect of local anesthesia with articaine plus 1:200,000 adrenalin versus lidocaine plus 1:100,000 adrenalin in medically compromised cardiac patients: a prospective, randomized, double blinded study. Oral Surg Oral Med Oral Pathol Oral Radiol Endod 2008; 105: 725-30.

28. Tomeva N, Deliverska E. Monitoring of vital signs and hemodynamic changes in patients undergoing tooth extraction and third molar surgery - literature review. J of IMAB 2020; 26: 3087-91.

29. Amoian B, Rabiee M, Aghvami M, Milani S. Evaluation of hemodynamic and $\mathrm{SpO}_{2}$ variability during different stages of periodontal surgery. J Indian Soc Periodontol 2013; 17: 612-6.

30. Alemany-Martínez A, Valmaseda-Castellón E, Berini-Aytés L, Gay-Escoda C. Hemodynamic changes during the surgical removal of lower third molars. J Oral Maxillofac Surg 2008; 66: 453-61.

31.Güngörmüş M, Dayı E, Büyükkurt C. Clinical research of the effects on pulse and blood pressure of two different local anesthetic solutions used normotensive and hypertensive Patients. OMU Diş Hek Fak Derg 2002; 3: 94-7.

32. Faraco FN, Kawakami PY, Mestnik MJ, Ferrari DS, Shibli JA. Effect of Ansethetics containing lidocaine and epinephrine on cardiovascular changes during dental implant surgery. J Oral Implantol 2007; 33: 84-8. 